\title{
La lconología como método de estudio historiográfico: los aportes a la historia del arte
}

\author{
The iconology as a method of historiographical study : contributions to the history of art
}

\author{
Daniel Montero Rodríguez ${ }^{1}$ \\ Recibido: 05/06/2015 / Aprobado: 12/04/2016
}

\begin{abstract}
Resumen
El presente trabajo consiste en un estudio teórico de la noción de iconografía, como método de estudio historiográfico, a partir de sus contribuciones a la historia del arte. En primera instancia, se abordan las concepciones tradicionales del término para después analizar las diversas propuestas teóricas que redefinen este método. De tal forma, se establecen los diversos estadios de la iconología y su doble dimensión teórico metodológica, dentro de los estudios semióticos de la historia del arte.
\end{abstract}

Palabras claves: iconografía, iconología, historia del arte, historiografía, pictórico, arte.

\section{Abstract}

This article is a theoretical review of the concept of iconography, as a method to conduct historiographical studies, based on its contributions to the history of art. Firstly, the traditional definitions of the term are addressed. Then, various theoretical proposals that redefine this method are analyzed. As a result, various stages of iconology and its double methodological theoretical dimension are established within semiotic studies of art history.

Keywords: iconography, iconology, art history, historiography, pictorial art.

\section{Introducción}

Para el estudio de las distintas manifestaciones estéticas surgidas a lo largo de la historia en las diferentes culturas, se originó un método de investigación historiográfico, este nuevo método, paralelo a la semiótica, pretende comprender la historia a través no solo de textos, sino de las propias formas icónicas representadas en las imágenes pictóricas de diversos períodos y culturas, en relación con otro tipo de documentos surgidos de estas.

Esa propuesta analítica es conocida como iconología. Se estudian los planteamientos pioneros del estudio iconológico como método de investigación historiográfico de las artes visuales, pero sin contemplar la perspectiva semiótica. Prioritariamente, se revisan sus logros particulares y los aportes brindados al estudio histórico del arte. No se pretende un compendio exhaustivo de lecturas, ni una descripción y caracterización de los planteamientos metódicos desarrollados por los especialistas en este campo; se confrontan estudios sobre las propuestas iconológicas, los cuales permiten revisar el constructo teórico denominado iconología, como análisis de la imagen y fuente de información, para la comprobación de su aporte y objeción dentro del estudio de la historia del arte.

Como punto de partida, se plantea una problematización general, la cual se puede resumir en la siguiente interrogante: ¿cuáles son los principales aportes del estudio iconológico al campo de la historiografía del arte, a partir del proceso de desarrollo abarcado desde su origen hasta su constitución como método investigativo?

${ }^{1}$ Profesor de Artes Plásticas, Departamento de Filosofía, Artes y Letras, Sede de Occidente, Universidad de Costa Rica. Correo electrónico: danielmont84@gmail.com 


\section{Acercamiento a la noción de iconología y al estudio historiográfico}

La mayoría de investigaciones sobre iconología mantienen una perspectiva de estudio donde conceptualizan este proceso o método, relacionado con la historia del arte. Pocas veces, dichos estudios evidencian la intención de realizar un análisis respecto al aporte brindado por la iconología al campo semiótico, en consecuencia, este se ha entendido como un sistema de análisis historiográfico, constituido por reflexiones enfocadas en diferentes periodos específicos. Estas reflexiones develan un interés centrado en el proceso que ha llevado al planteamiento de la iconología como método. Sin embargo, se observa una ausencia de estudios sobre las contribuciones ofrecidas por la iconología, como instrumento analítico, al estudio historiográfico del arte.

Para comprender el aporte de la iconología al ámbito histórico del arte, es pertinente comprobar la relación de este método con la historiografía. De esta manera, se pueden encontrar aquellos aspectos pertinentes y novedosos para la investigación histórica.

La iconología, como método de análisis para estudiar contextos y hacer (re)lecturas de los sucesos históricos, se fundamenta en el hecho primordial de investigar mediante la concepción de obra pictórica como ícono. El entendimiento pleno de cómo la imagen remite a situaciones contextuales e históricas, requiere abordar el sentido primero de la palabra "ícono". El Diccionario de retórica y poética (1995) propone su significado en relación con el término "signo", se alude de esta forma al sentido simbólico de la imagen: "En general, todo fenómeno u objeto que representa algo que generalmente es distinto, a lo cual sustituye al referírsele. Es decir, todo dato perceptible por los sentidos (visual, auditivo, etc., por ejemplo un síntoma) que, al representar (pues es representante) algo no percibido, permite advertir lo representado (por ejemplo la enfermedad)" (Beristáin, 1995, p. 450). En este sentido, se presenta la imagen como ícono en tanto signo, al ser representativo de otro aspecto; el sentido de representación es lo que carga a la obra de un valor simbólico y, a su vez, la convierte en materia prima del estudioso iconológico, semiótico e histórico.

Asimismo, al relacionarse la iconicidad con un sentido simbólico-representativo, se constituye en un elemento que remite a otro, dentro de la realidad no visual. Entonces, según Algirdas J. Greimas, "las cosas" son cargadas con un sentido simbólico del que se apropia el artista para lograr la re-presentación de la imagen:

(...) cada cultura, al estar dotada de una «visión del mundo» que le es propia, les plantea también condiciones variables al reconocimiento de los objetos y, con ello, a la identificación de las figuras «que representan» los objetos del mundo, conformándose a menudo con vagos esquematismos, pero exigiendo a veces una reproducción minuciosa de los detalles «verídicos» (2002, p. 80).

De este modo, queda claro cómo la imagen pictórica, al ser representación de la realidad, posee cierto simbolismo del que se apropia el estudio iconográfico para releer la historia a través de estas imágenes.

En relación con lo anterior, se entiende a la obra de arte no sólo como elemento de estudio dentro de la cultura, sino como documento por medio del cual se puede descubrir la relación histórico-cultural de una época. Por ello, se propone como método de estudio analizar la obra visual en determinado periodo:

Esta corriente metodológica, en contraposición a la Escuela de Viena, se centra en el contenido de la obra de arte, es decir, en el "qué dice", aunque sin por ello desdeñar el "cómo lo dice". Por otro lado, se aboca al estudio de la transmisión de los temas del arte antiguo a través de la Edad Media y su resignificación en el Renacimiento. Su principal aporte ha consistido en el hallazgo de indicios que permitan armar una cadena de relaciones fundadas y eslabones verificables entre textos, imágenes, ceremonias, prácticas sociales y culturales para llegar a una cabal comprensión de las obras de arte (Agesta, 1989, p. 4). 
De esta manera, se puede comprender cómo la obra de arte manifiesta ciertas situaciones socioculturales que revelan parte de la historia a la cual pertenecen y responden a preguntas como "¿qué dice?” y “¿cómo lo dice?” Por lo tanto, se generan conexiones entre arte, cultura y sociedad, las cuales brindan un conocimiento artístico contextual. Así, parte de la importancia de la iconología como estudio, es el hecho de que propone la obra de arte como objeto de análisis $\mathrm{y}$, a su vez, plantea una revisión cruzada donde se relaciona la imagen plástica con otros textos (literarios, históricos, antropológicos, entre otros), para comprender la obra en su periodo.

La capacidad simbólica de la imagen pictórica como ícono y, por lo tanto, como representante, es lo que le brinda la cualidad de documento analítico. Asimismo, esta se establece como texto crítico dentro de la investigación, tanto al considerarla en el estudio semiótico -cuando remite al signo-, como en el estudio historiográfico, al contemplarla como documento histórico.

Por todo esto, el estudio de los aspectos y las fases fundamentales del estudio iconográfico, permite observar cuáles fueron esos aportes que lo postularon como instrumento de análisis históricoartístico y, sobre todo, qué lo llevó constituirse en método historiográfico. Este método de análisis posee tres estados, en los cuales se observa su proceso de transformación. Estos son identificados mediante las figuras más representativas de la iconología: Abraham Moritz "Aby" Warburg (18661929), Erwin Panofsky (1892-1968) y Ernst Hans Josef Gombrich (1909-2001). Al estudiar cada una de estas fases, se comprende su genealogía básica, los planteamientos esenciales del método y, a su vez, se identifican sus contribuciones a la investigación historiográfica (en el entendido de la forma de sus fuentes, documentación y análisis).

La propuesta de Vasari sobre las "Vite" se consideraría como antecedente de la sistematización investigativa iconográfica. Así lo señala Yvars, cuando propone una relación entre biografía y obra de artistas, a través de lo que se entendería como una pinacoteca, donde Vasari logra no solo catalogar gran cantidad de obras, sino que, al relacionarlas con las biografías artísticas, consigue una congruencia intrínseca y devela un estudio entre obra y autor.

De hecho, la originalidad de la contribución de Vasari, a que le ha valido el título de "padre fundador» de la historiografía de arte, reside sobre todo en su esfuerzo de articulación -ya que no sistematización- de los abundantes materiales con los que cuenta. [...] Vasari se hizo incluso con una colección de dibujos -su libro de'disegni- de cientos de obras debidas a decenas de artistas, lo cual le permitiría reducir la dependencia respecto de la impresión inmediata y la memoria, desplegar su texto a partir de un nivel de reflexión hasta entonces desconocido. Las Vite no son ya un simple elenco de biografías yuxtapuestas acompañadas de un catálogo de obras (Yvars, 2004, p. 137).

Precisamente, es la incorporación de la obra artística como documento referencial dentro de la investigación histórica -en el trabajo de Vasari-, lo que se propone como una primera incursión dentro del campo iconográfico. Si bien la obra no se analiza semióticamente desde su iconicidad (o lo simbólico), sí se propone como texto testimonial, portador de información provechosa para la historia del arte. No obstante, el trabajo de Vasari no se contempla como un estudio iconológico: "De hecho, como ha señalado Germain Bazin, Vasari creó «no una nueva ciencia, sino un nuevo género literario»: «no la historia del arte, sino la novela de la historia del arte»" (Yvars, 2004, p. 138). Ese sentido narrativo de la historia del arte en Vasari, es a lo que alude Yvars cuando deja en claro la falta de objetividad crítica del estudio, pero, también observa un aspecto importante en el trabajo de Vasari, cuando incorpora un nuevo lenguaje al estudio histórico, el cual se apodera de la imagen como fuente de información.

Si bien el estudio de Vasari solo se contempla como una articulación de obras de arte con biografías, y no como una sistematización, es correcto comprender este como un primer paso hacia la metodología icónica, pues plantea un estudio 
a través del objeto artístico. Sin embargo, la imagen como fuente va a ser propuesta por Aby Warburg: "Esta metodología en el estudio de la historia del arte se desarrolla en Alemania, durante el periodo de entre guerras, paralelamente al formalismo y de la mano de Aby Warburg (1866-1929), quien en 1920 funda un Instituto en Hamburgo (...)” (Agesta, 1989 , p. 4).

En un primer momento, se observa un aporte antecedente al método; es decir, cómo surge y en qué forma se interpretan los precedentes del estudio. En esta etapa, se tiene la propuesta de Abraham Moritz "Aby" Warburg, crítico enfocado en varias formas de investigación. Sin embargo, su más reconocido trabajo dentro de la historiografía tiene que ver con la inquietud por el artista y la obra de arte como expresión de la mente humana. En este aspecto difiere con Horne ${ }^{2}$, quien solo se ocupa del conocimiento de la vida del artista. Según Fritz Saxl, en su texto Tres "florentinos»: Herbert Horne, A. Warburg y Jacques Mesnil, esto se debió a que el propósito de Warburg era la psicología histórica:

Pero su preocupación original por el artista y la obra de arte aislada se desarrolló hacia un interés más amplio por toda la imaginieria, por la imaeginería [sic] como expresión de la mente humana. Este es el primer punto en el que difiere esencialmente de Horne, cuya investigación se dirigía sólo [sic] hacia la comprensión de la vida y las obras del artista aislado. Un estudio como el de Warburg no podía limitarse al arte. Puesto que el propósito de Warburg era la psiciología[sic] histórica, las formas artísticas habían de estudiarse en relación con otras expresiones de la mente humana (Saxl, 1989, p. 305).
El interés de Warburg es interpretar la historia en la imagen. Esto no solo como hecho representativo de la imagen, sino estudiar lo que define como "psicohistoria": así, plantea un estudio sociocultural de la obra, o sea una historia del arte. En relación con lo anterior, se encuentra el texto de Juan Antonio Ramírez, Iconografía e iconología, donde explica cómo se llega a este pensamiento, mediante una influencia del psicoanálisis freudiano en la obra de Warburg:

El nexo entre la dimensión subjetiva y el estudio científico de la historia estaba claro para Aby Warburg, mucho más comprometido personalmente con el pasado de lo que se ha solido imaginar. "A veces me parece escribió en su Diario el 3 de abril de 1929como si, en mi papel de psicohistoriador [Psichohistoriker], tratase de diagnosticar la esquizofrenia de la civilización occidental a través de sus imágenes en un reflejo autobiográfico. La ninfa extática (mánica) de un lado y el afligido río-dios (depresivos) de otro...» (Ramírez, p. 298 16).

De esta forma, el "psicohistoriador" deja claro que trata de entender o diagnosticar cómo funcionaba la civilización a la cual pertenecen las imágenes que estudia. Con esto, al investigar las culturas a través de las imágenes, establece una nueva forma de ver la obra artística, ahora como fuente de información para el análisis historiográfico.

Ramírez afirma que estos planteamientos sobre el estudio de la obra a posteriori, como trabajo pictórico y no desde lo que el pintor quería decir, son seguidos por Dalí y Panofsky ${ }^{3}$. Sin embargo,

\footnotetext{
${ }^{2}$ Para quienes no conocen a Herbert Honer, este es uno de los florentinos (Tres «florentinos »: Herbert Honer, A. Warburg y Jacques Mesnil de Fritz Saxl) considerado el historiador del arte más destacado. Nació en 1864, cuando aún la historia del arte no era reconocida como ciencia, fue arquitecto, poeta, pintor, esteta e historiador. La obra de su vida fue el libro sobre Botticelli. Llegó a relacionarse con personajes como: William Morris, Oscar Wilde y Walter Peter (Saxl, 1989, pp. 297-300). Por otra parte, es altamente reconocido por su aporte a la Crítica histórica, como hace saber Fritz Saxl cuando habla sobre el trabajo de Horne: "Día tras día, año tras año, iba a iglesias, palacios y galerías para aprender a distinguir con certeza entre la obra de Botticelli y la de sus discípulos. La crítica histórica de todas las fuentes disponibles, pictóricas, literarias y documentales, se convirtió en la obra de su vida" $(1989$, p. 299).
} 
en relación con esta, el interés se enfoca, no en la influencia psicoanalítica, sino en la propuesta de Warburg de plantear la obra pictórica como fuente de análisis, a través de la cual se puede estudiar la expresión de la mente humana.

Mantenerse, pues, la hipótesis de una influencia pendular: en un primer momento Freud influye sobre Warburg; en un segundo estadio, la escuela iconológica contribuye a que Dalí defina mejor su método paranoicocrítico. Pero no es necesario aceptar esta segunda parte para explicar las coincidencias: la iconología y la paranoia-crítica parten de un rechazo común del pensamiento dialéctico (Ramírez, p. 304 19).

Así, se observa un interés por la relación entre "forma" y "significado" (contenido); o sea, la correspondencia entre el ícono y lo que puede referirse de este como signo. Esta es la esencia de la iconografía, interpretar la historia de la cultura a través de sus imágenes.

Respecto al estudio de la imagen como documento analítico de la iconografía, se debe contemplar no solo la influencia de Freud sobre Warburg, como Juan Antonio Ramírez afirma. También, se debe observar la sucesión de Burckhardt dentro de su trabajo, como propone José Francisco Yvars en La formación de la historiografía: "De lo que se trataba era de proseguir la tarea de Burckhardt en pos de una historiografía donde el arte apareciese rigurosamente inscrito en el contexto cultural, ideológico e icónico que le conferiría su sentido" (2004, p.148). Esta evidencia el interés por contextualizar la obra de arte, a través de la información simbólica que brinda la obra visual.
La idea de interpretar la obra plástica como texto portador de información de su contexto, es comentada por Carlo Ginzburg en la obra De A. Warburg a E. H. Gombrich: notas sobre un problema de método (1989), esto lo hace a través del trabajo de Wind, cuando explica que: "[...] Warburg había deducido de Burckhardt: una "cultura" entendida en un sentido casi antropológico, en la que, al lado del arte, de la literatura, de la filosofía, de la ciencia, encontraban un lugar las supersticiones y las actividades manuales" (1989, p. 43). El autor entiende esto como una unidad cultural, pues toda la información del contexto remite a la propia identidad sociocultural, asumiendo un sentido consustancial. Asimismo, en este planteamiento, la referencia visual mantiene una relación con otros textos culturales, los cuales establecen con claridad la relación histórica entre ellos.

Estos textos no solo rescatan el aporte de la imagen como fuente de información para la historia artística, sino, a su vez, establecen las relaciones que un estudio con esta característica genera, respecto a la literalidad de los documentos.

La imagen, como materia de estudio de la iconología, debe verse referida a otros textos que justifiquen el análisis historiográfico. Esto lo explica Antonio Ramírez, cuando hace referencia al modo de operar de la dependencia literaria del estudio, de modo que la obra es referida a textos literarios (mitológicos, orales, leyendas) o a la inversa, al revisar los textos con imágenes de temática similar. El crítico propone esto como un acercamiento de la iconografía y, por ende, de la historiografía, a otras disciplinas humanistas (literatura, filosofía, teología, mitología, entre otras). Explica:

\footnotetext{
3 En cuanto a Panofsky, la estudiosa Estrella de Diego deja clara esta posición del pensador; asimismo esta autora plantea a Warburg y otros como pioneros del método, en la introducción a Idea de Erwin Panofsky: "En los años 20 los cimientos de la historia del arte empiezan a consolidarse de la mano de nombres luminosos como Riegl, Wölffin y Warburg -este último decisivo para Panofsky (Ferretti, 1989)-, quienes entre mediados de las décadas de los años ochenta y finales de los noventa de 1800 elaboran los principios fundamentales de la disciplina tal y como se la conoce" (Panofsky, 2013, p. 9).
} 
No puede olvidarse esta dependencia «literaria» de la iconología clásica, una disciplina que está basada, casi siempre, en el siguiente procedimiento de trabajo: el estudio fija su atención en una obra artística y a continuación descubre un texto o conjunto de textos, más o menos coetáneos, a los que remite la representación visual en cuestión; el proceso también puede ser el inverso: se tiene o se conoce un texto y luego se busca (o se encuentra) alguna imagen que lo ilustra (Ramírez, p. 294).

Ramírez expone no sólo la dependencia de la iconografía, como método analítico, de otras fuentes que justifiquen su relación contextual, sino que propone la literalidad necesaria para narrar la historia del arte. Este es un aporte al estudio histórico, pues se relaciona con lo que Enrique Florescano denomina como "Fase documental y la Representación histórica”; ya que, en la primera, se toma esa apertura de la imagen como documento $y$, en la segunda fase, se contempla la relación literaria de la investigación, no solo como proceso de objetivación (veracidad del estudio), sino como aporte de la narrativa de la literatura a la narrativa histórica.

La fase documental comienza con la declaración que hace el testigo de su experiencia, que es una declaración oral y personal, referida a un hecho vivido en un lugar y un tiempo precisos. Pero para adquirir la categoría de testimonio esa declaración es sometida a distintas pruebas de veracidad hasta llegar a ser considerada un testimonio fiable, garantizado. Cuando advino la escritura, el testimonio oral se convirtió en texto (Florescano, 2012, p. 260).

Por otra parte, no se puede dejar de lado la segunda etapa del trabajo de Florescano: la "Fase explicativa-comprensiva". En esta se plantea que, tanto el texto como la imagen, deben pasar por la interpretación del estudioso, así como por la verificación de los hallazgos: "Finalmente, el proceso de comprensión y explicación puede resumirse en el objetivo de interpretar adecuadamente los hechos examinados [...]" (Florescano, 2012, p. 268). En este sentido, plantea tanto la veracidad que debe poseer el texto pictórico en su relación histórico contextual, como el cuidado que se debe tener con el referente visual, dentro del estudio iconológico. Así, el sentido de subjetividad u objetividad que puede abarcar la representación sígnica de la iconicidad, es un asunto que debe ser atendido por el estudioso, si pretende realizar un análisis objetivo, a la vez que concederle a la obra ese sentido referencial.

Al contemplar la obra plástica como representante $y$, en tanto documento histórico, es preciso observar la capacidad crítica que esta brinda. Es decir, es necesario estudiar la facultad objetiva de este nuevo texto y observar con ojo crítico la posibilidad de ser un fiel representante del contexto o de cierta situación. Este proceso es estudiado por Enrique Florescano, en su texto Tres pilares de la operación historiográfica (2012), donde señala una fase documental, la cual cuestiona la veracidad de los diferentes tipos de documentos a los que puede remitir el investigador. Esto es interpretado por Ramírez como un proceso de carácter interdisciplinar, observado al contemplar el aporte de la literalidad al estudio de la iconicidad:

Consecuencia de semejante posición metodológica fue el acercamiento de la historia del arte a otras disciplinas humanísticas como la literatura, filosofía, teología, mitología, etc.: puesto que no parecía posible sin ellas saber cuáles eran muchos de los temas del arte, era inevitable que semejantes materias legaran a concebirse como parientes cercanos de la creación plástica (Ramírez, p. 294).

En consecuencia, esto resulta en otro aporte de la iconografía a la historiográfica del arte, al recurrir a la verificación de los estudios icónicos a través de otras fuentes de información, así como contextualizar épocas mediante sus producciones culturales, releídas a la luz de las imágenes analizadas. Este trabajo de interdisciplinaridad es relevante, ya que plantea nuevas fuentes de investigación, a la 
vez que las relaciona entre sí, logrando análisis que procuran la objetividad del estudio.

Lo anterior se vincula con la propuesta de Erwin Panofsky, pues su trabajo se considera como la sistematización del método iconográfico, donde se tiene una faceta interpretativa y novedosa para el estudio, la cual debe poseer un carácter objetivo. Esto se postula como un segundo estadio, dentro del proceso de transformación de la iconografía como método de investigación, en la historia del arte.

El trabajo de Panofsky considera la sistematización del estudio iconológico, pues, a diferencia de los anteriores que solo realizaban investigaciones de este tipo, este iconólogo se preocupa por esclarecer sus pasos metodológicos. Plantea el "significado fáctico y el expresivo" (preiconográfico), como una primer etapa de análisis, donde se estudia la imagen de manera descriptiva; otro significado sería "secundario o convencional" (iconográfico), y señala un estudio sobre historias o alegorías en las imágenes; por último, propone una nueva fase, el "significado intrínseco o contenido", donde estudia la imagen a profundidad y en relación con valores simbólicos:

Ante una obra de arte comenzamos por esclarecer su asunto primario o natural (forma y expresionismo), o etapa que Panofsky llama pre-iconográfica, en la que empleamos de primera mano nuestra experiencia práctica en reconocer o describir objetivos o hechos. [...] análisis propiamente iconográfico, es decir al tema que hemos llamado secundario o convencional (el asunto constituido por lo que llamamos imágenes, historias o alegorías). [...] Panofsky llama el significado intrínseco o contenido (content) el que comporta valores simbólicos, empleando este término en el sentido en que lo usa el neo-kantiano Ernst Cassirer, entramos en el campo de la interpretación iconológica [...] (Ferrari, 1992, p. XXXII).
Por otra parte, esta última faceta es conceptualizada por Ripa como iconología: "Aunque en el fondo el contenido era puramente iconográfico, todos seguían a Ripa en el empleo de la palabra iconología" (González, 1989, p. 6). Así, es Panofsky quien trabaja esta propuesta de manera novedosa; pues, se podría decir que busca contextualizar la obra pictórica a través de un proceso interpretativo.

"La Iconología en su nuevo significado", como lo establece el crítico Martín González, es la postura novedosa que plantea Panofsky ante el estudio iconográfico, cuando sistematiza este trabajo. Para lograr esto, establece los pasos metodológicos del estudio. González explica que este trabajo pretende una contextualización la cual establezca, con precisión, el objetivo investigado por medio de la imagen.

La Iconología se ocupa del origen, transmisión y significado profundo de las imágenes. Es el grado último que permite comprender la imagen; el soporte es la iconografía. No hay iconología sin iconografía. La diferencia esencial es que la iconología se contempla como un hecho histórico global, de suerte que se reclaman para su entendimiento todos los elementos que componen el tejido del pasado. Por eso la iconología, más que rama de la historia del arte, lo es de la cultura y del pensamiento (González, 1989, p. 7).

Lo anterior permite observar el anhelo de Panofsky por contemplar un estudio global, enmarcado en la totalidad contextual -el espíritude una época, lo cual es extremadamente ambiguo y ambicioso. Pasa, así, de lo que buscaba Warburg, una "historia del arte", a lo que Panofsky pretende como "cultura y del pensamiento". Este es el aporte de Panofsky a la iconografía, la contextualización total de una imagen, o sea un amplio marco ideológico para ubicar y estudiar el ícono.

\footnotetext{
${ }^{4}$ Para mayores referencias y ejemplos sobre esta los términos: Significado fáctico y expresivo, Secundario o Convencional y Significado intrínseco o contenido, véase Capítulo 1 INTRODUCCIÓN del texto Estudios sobre iconología de Erwin Panofsky. Madrid: Alianza Universidad, 1992.
} 
Dentro del estudio de la iconología, se encuentra otro crítico que llega a plantear el método como "instrumento" de análisis. Según Ginzburg, la influencia de Warburg sobre Saxl lleva a este último a proponer nuevas nociones para el método: "Arnaldo Momigliano ha señalado con justicia que, frente a la amplitud de intereses y a la variedad de aproximaciones propias de Warburg, Saxl tiende a privilegiar el análisis iconográfico, hasta hacer del mismo un instrumento de reconstrucción histórica general (Ginzburg, 1989, p. 49). Saxl no solo establece la iconográfica como instrumento, sino que considera una "reconstrucción histórica"; esto significa, nuevas lecturas para la imagen pictórica y para la propia historia general del arte. De esta forma, señala -para la historiografía- el hecho de releer las narraciones históricas tenidas por ciertas.

Ahora, con este nuevo punto de vista, el pensamiento de Saxl concibe, a través de una serie de ensayos, un aspecto fundamental que Carlo Ginzburg menciona como "historia de la cultura". Esto consiste en que el conocimiento general del iconólogo es estudiar la historia en general; así establece la interdisciplinaridad, como parte fundamental en un estudio iconológico.

En esta clase de ensayos, Saxl saca partido de una erudición vastísima, que no conoce limitación temática alguna: historia política, egiptología, mitografía del siglo XVI, son convocadas a resolver problemas que siempre se encuentran circunscritos y determinados pero que, una vez resueltos, nos introducen en un contexto más amplio, que hasta podríamos llamar (siempre que la expresión no evoque una Geistesgeschichte descolorida y abstracta) de historia de la cultura (1989, p. 50).

En cuanto al aspecto de interdisciplinaridad implicada e el trabajo analítico del método, se presenta con mayor exactitud cuando E. Garin -al que refiere Ginzburg en De A. Warburg a E. H. Gombrich- habla sobre los trabajos de Saxl y Panofsky. Garin contempla no solo ese aspecto de interdisciplinaridad, sino una precisión filosófica, así como una ruptura con la tradición académica:
Por lo tanto, al delinear "lo que en el trabajo de Panofsky y Saxl era el aspecto más importante, es decir en método y un tipo de investigación" [...], Garin insiste en los siguientes puntos: concreción y precisión filosófica, adhesión a las cosas [...]; planteamiento interdisciplinario, ruptura de las diferentes academias o sencillamente dictadas por la tradición. Estas serían -más allá de las vetas de investigación, importantísimas, descubiertas o profundizadas por estos estudiosos- las características esenciales del método "warburguiano", que garantizarían su fecundidad y su ejemplaridad (Ginzburg, 1989, p.45).

De esta forma, el estudio se presenta como un doble cambio para la metodología ordinaria: por un lado, al investigar la historia y, por otra parte, al servir de apertura a las fuentes y relaciones teóricas cuando se indagan las obras artísticas. El estudio interdisciplinar es fundamental, pues es la contribución de Saxl a la iconología; a su vez, evidencia la importancia de un acervo cultural e intelectual que explique cada aspecto del análisis, al estudiar una imagen.

Relacionar la iconicidad de una imagen y su simbología con otros aspectos teóricos, sociales y culturales, permite reconstruir no solo el contexto sociocultural, sino develar un completo sentido de la historia del arte. La vinculación de las artes con la historia general, es la propuesta de Saxl como iconólogo.

Peter Berger, en su texto El uso de la imagen como documento histórico, propone que "sin un conocimiento razonable de la cultura clásica, somos incapaces de leer muchas obras de la pintura occidental" (2005, p. 47). Esto viene a apoyar lo mencionado anteriormente, sobre el cocimiento general que debe formar parte del estudioso. Así mismo, Berger expone cómo se puede realizar no solo un enlace entre los textos y las imágenes, sino, relacionar otras imágenes con las que están en proceso de análisis: 
Apartándonos por un momento de las interpretaciones y fijando nuestra atención en el método que ejemplifican, debemos señalar tres puntos. El primero es que, al intentar reconstruir lo que suele llamarse "programa» iconográfico, los estudiosos a menudo ponen en relación imágenes que los acontecimientos habían separado, es decir, cuadros que originalmente se suponía que debían ser leído juntos, pero que en la actualidad se hallan dispersos por museos y galerías de todo el mundo (Berger, 2005, p. 49).

El crítico plantea que Saxl realiza esto al fijar su atención en el método, refiriéndose tanto a las propuestas de Warburg como a las de Panofsky. Según Berger, Saxl expone anticipadamente lo que Peter Wargner conoce como "iconotexto", al nominar el elemento sobre el cual la iconografía hace su estudio y aumentar la perspectiva existente del aporte del método a la historiografía.

El tercer punto es que los iconógrafos normalmente se dedican a yuxtaponer textos y otras imágenes a la imagen que pretenden interpretar. Muchos de esos textos se encuentran en las propias imágenes, en forma de cartelas o inscripciones, convirtiendo la imagen en lo que el historiador del arte Peter Wagner llama un «iconotexto», susceptible de ser «leído» por el espectador literal y metafóricamente (Berger, 2005, p. 50).

En este sentido, se puede apreciar cómo estaría dirigida la investigación, dentro del estudio de lo que se ha considerado como los dos primeros estados de la propuesta iconológica, y sus aportes a la metodología historiográfica del arte. Primero, se observaría un antecedente del trabajo, para luego ver las influencias de Freud y Burckhardt sobre el trabajo de quien se estima es el padre de la iconología, Warburg. Con esto se consideran los primeros beneficios del estudio histórico: en primer lugar, contemplar la imagen como documento, al sumar fuentes de información al entendido investigativo. Por otra parte, agrega saberes al estudio de la iconicidad, contribuyendo con la forma de entender y hacer la historia, a través de formas literarias para el análisis; en el segundo caso, se tiene la sistematización del método y se percibe el trabajo de Panofsky como un aporte al agregado iconológico, donde pretende un estudio interpretativo (cargado de un gran carácter objetivo), el cual procura lo que se consideraría como una contextualización de la imagen. A su vez, esto propicia un proceso de mayor conocimiento sobre épocas del arte, así como un aumento en los conocimientos posibles de abarcar con el estudio, para finalmente llegar a lo que Saxl contempla como interdisciplinaridad del procedimiento analítico.

Por otra parte, en lo que sería un tercer estadio de la iconología, se tiene la crítica al método, así como una nueva posibilidad de interpretar la iconográfica como estudio historiográfico. Ernst Hans Josef Gombrich mantiene una actitud de recelo con respecto a la última fase del método de Panofsky, "significado intrínseco o contenido" (iconológico), de hecho, lo rechaza por completo, tal como asevera Carlos Montes Serrano, en Estilo e iconología en E. H. Gombrich. Una revisión crítica al pensamiento de Erwin Panofsky:

Gombrich rechaza radicalmente todo este planteamiento, pues entiende que, si bien hay una cierta verdad en el postulado que afirma que existe una íntima conexión entre las distintas manifestaciones de una cultura, no nos es lícito postular que todos los aspectos de esa cultura se relacionen con una causa rectora, con un centro común, con unos principios subyacentes de las que estas manifestaciones son meras consecuencias (Montes, 1989, p. 3).

Precisamente, esta contextualización extrema de la obra de Panofsky -quien pretende vincular la imagen con otros textos sociales y culturales, a través de un sentido considerablemente unificado de la época representada en la iconicidad de la imagen-, es lo que Gombrich refuta drásticamente. Esto es ratificado por Carlo Ginzburg, cuando diserta sobre la desconfianza en el sistema, la cual cierne sobre la relación entre la imagen y el contexto donde es realizada: 
En conclusión, es muy comprensible que en la disertación académica que acabamos de citar, Gombrich ponga en guardia a los historiadores del arte en cuanto a 'considerar los estilos del pasado como una mera expresión de su tiempo, de su raza o de su situación de clase’ (la unión de los dos últimos términos es característica de los presupuestos ideológicos del autor); pero surge la clara impresión de que esa insistencia implica un escaso interés, o, mejor aun, una notable desconfianza hacia la investigación de los vínculos entre la obra de arte y la situación histórica en la cual ésta nace" (Ginzburg, 1989, p. 64).

Gombrich sospecha de que los estilos sean una manifestación clara de la época a la cual pertenecen. Esto se debe a que se consideran como una idea cargada de sentido ambiguo, pues no se puede presuponer que el artista premedita exponer o representar con fidelidad su época y, si esto fuera así, es necesario fragmentar y seleccionar qué tanto de la época es lo que se está estudiando. De tal modo, según Gombrich: "El arte no refleja el espíritu de la época, ya que esta noción es demasiado vaga para ser de alguna utilidad" (2003, p. 272). Para el crítico, es mucha la información que se pretende decodificar en los textos pictóricos.

Sin embargo, el crítico contribuye con el método iconológico, cuando establece una vinculación entre las diferentes imágenes del arte, al relacionar la obra artística con otras con las cuales pueda tener alguna correspondencia. De este modo, propone que colaboren en la elucidación del estudio. Asimismo, formula que las manifestaciones artísticas no son inconexas: "Una vez más resulta claro que, para Gombrich, afirmar que el arte tiene una historia significa simplemente subrayar que las diversas manifestaciones artísticas no son expresiones inconexas, sino eslabones de una tradición. El problema de la modificación estilística sigue abierto" (Ginzburg, 1989, p. 69). Relacionar las imágenes intertextualmente es lo que Gombrich aporta a la iconología. Las congruencias ideológicas que se manifiestan entre las imágenes, constituyen la forma de realizar el estudio, sin prentender la comprensión total del "espíritu de la época".

Con esto, Gombrich no solo deja abierto el problema del estilo, que es la base de su crítica hacia la programación de Panofsky, sino que arroja nuevas luces sobre la forma de estudiar la historia a través de los íconos:

Podríamos decir, por tanto, que en los años ochenta Gombrich ha llegado a ocupar el hueco dejado por Erwin Panofsky (18921968) hace ahora veinte años; sustituyendo el peculiar enfoque metodológico de éste, en la investigación histórico-artística, por un pragmatismo crítico, racionalista y científico (Montes, 1989, p. 1).

Se delimita la propuesta de Gombrich como una modificación al método iconológico de Panofsky, y como un aporte al estudio iconográfico de Warburg. De esta manera, el proceso que ha establecido el método iconográfico-iconológico, como se conoce actualmente, consiste en un desarrollo donde distintos aportes son dados a las formas de estudio de la historiografía.

\section{Conclusiones}

La indagación acerca del proceso de la iconología como método de estudio de la historiografía, a través de los protagonistas desarrolladores de este como sistema, permite identificar diferentes etapas e interpretaciones. Tales contribuciones a la iconología, la constituyen en un método de investigación para la historia del arte y su historiografía.

Inicialmente, Warburg presenta no solo a la imagen como fuente de información para la historia, sino que propone la individualidad de una historia del arte; estudiar esta como factor particular, pero, indiscutiblemente, vinculado con lo sociocultural y su época. Warburg plantea la obra pictórica como documento de análisis, a través del cual se puede estudiar la expresión de la mente humana como referencia de sus imágenes.

Por otra parte, Antonio Ramírez expone que, tanto en el trabajo de Warburg como en el 
de Panofsky, las fuentes deben ser justificadas en su relación contextual. A su vez, estos críticos proponen la literalidad necesaria para narrar la historia del arte, y el aporte entre la relación de las imágenes como textos con otros textos, al desarrollar la narrativa histórica necesaria. Asimismo, esto propicia un análisis objetivo, el cual concede a la obra ese sentido referencial con el cual se aseguran las afirmaciones hechas a través de la iconicidad.

Según Ginzburg, mediante la influencia de Warburg sobre Saxl, se plantea la iconográfica como "instrumento". Asimismo, establece una "reconstrucción histórica" cuando plantea, para la historiografía, el hecho de releer las narraciones históricas tenidas por ciertas, a través de una interdisciplinaridad. De tal modo, se vuelve parte fundamental del estudio iconológico, el hecho de leer las imágenes a la luz de otras fuentes y conocimientos que justifiquen las averiguaciones.

Para finalizar, la correspondencia intertextual entre imágenes, sin prentender la comprensión de la totalidad del "espíritu de la época" (que es parte de su crítica), es el aporte de Gombrich a la iconología. Esto dada la referencialidad entre las formas icónicas, lo cual expone congruencias que permiten vislumbrar la historia del arte a través de los textos que contextualizan el estudio, pero, sobre todo, por medio de las imágenes y su relación como representantes de épocas históricas.

De esta manera, se comprende la iconología primero- al tener la imagen como fuente, su relación con la literalidad y como estudio interdisciplinar. Luego, se percibe su sitematización como instrumento para entender la historia del arte. Estas son las propuestas que se contemplan como aportes a la historiografía y al estudio de la historia del arte.

De esta manera, la iconología se concibe a través de dos dimensiones. Primero, al tener la imagen como fuente, su relacion con la literalidad y como estudio interdisciplinar. En segunda instacia, al ser percibida como sistematizacion instrumental para la compresión de la historia del arte. Estas son las pruebas que sirven de aporte fundamental a la historiografía y, sobre todo, al estudio de la historia del arte.

\section{Bibliografía}

Agesta, M. d. (1989). La historiografía del arte: Principales corrientes y claves de lectura. Recuperado de http://ecaths1.s3.amazonaws. com/historiadelarteylacultura/Corrientes $\% 20$ historiograficas\%20-\%20apunte.pdf

Berger, P. (2005). El uso de la imagen como documento histórico. Barcelona: Crítica.

Beristáin, E. (1995). Diccionario de retórica y poética. México: Porrúa.

Ferrari, E. L. (1992). Introducción a Panofsky (Iconología e historia del arte). En E. Panofsky. Estudios sobre iconología. Madrid: Alianza Editorial, (pp. IX-XL).

Florescano, E. (2012). Tres pilares de la operación historiográfica. En La función social de la historia. México: Fondo de Cultura Económica, (pp. 259-277).

Ginzburg. (1989). De A. Warburg a E. H. Gombrich. En C. Ginzburg, Mitos, emblemas, indicios. Morfología e historia. Barcelona: Gedisa, (pp. 38-93).

Gombrich, E. (1993). Tributos. Versión cultural de nuestras tradiciones. México: Fondo de Cultura Económica.

Gombrich, J. (2003). Lo que el arte nos dice. En: J. Gombrich. Los usos de las imagenes. Estudio sobre la función social del arte y la comunicación visual. México: Fondo de Cultura Económica, (pp. 262-272).

González, J. M. (19 de Mayo de 1989). Iconografía e iconología como método de la historia del arte. Revista virtual de la fundación universitaria española. Disponible en: http://www.fuesp. com/revistas/pag/cai0303. (consulta 01-062014). 
Greimas, A. (2002). Semiótica figurativa y semiótica plástica. En D. Navarro, Imagen 1. Teoría francesa y francófona del lenguaje visual y pictórico. La Habana: Criterios, (pp. 73-97).

Montes Serrano, Carlos. (1989). Estilo e iconología en E. H. Gombrich. Una revisión crítica al pensamiento de Erwin Panofsky. Revista virtual de la fundación universitaria española. Disponible en: http://www.fuesp.com/ revistas/pag/cai0451.html (consulta 01-062014).

Panofsky, Erwin. (1992). Estudios sobre iconología. Madrid: Alianza Universidad.

Panofsky, Erwin. (2013). Idea. Madrid: Cátedra.

Ramírez, J. A. El método iconológico y el paranoicocrítico. Universidad Autónoma de Madrid. Disponible en: http://www.uv.es/dep230/ revista/PDF340.pdf (consulta 20-04-2015).

Saxl, F. (1989). Tres «florentinos»: Herbert Horne, A. Warburg y Jacques Mesnil. En F. Saxl, La vida de las imágenes. Madrid: Alianza, (pp. 296-307).

Saxl (1989). ¿Por qué historia del arte? En F. Saxl, La vida de las imágenes. Madrid: Alianza, (pp. 308-318).

Yvars, J. (2004). La formación de la historiografía. En V. Bozal, Historia de las ideas estéticas y de las teorías artísticas contemporáneas. Madrid: A. Machado libros, (pp. 134-149). 